\title{
A Study of Clinical and Etiological Profile of Anaemia in Geriatric Patients in a Tertiary Care Hospital
}

\author{
R P Buden ${ }^{1}$ \\ ${ }^{1}$ M.D. Gen Medicine, Assistant Professor, Dept of Gen Medicine, SSIMS Medical College, T Begur NelamangalaTq, Bengaluru Rural Dist.
}

\section{Abstract}

Background: Geriatric anemia is a global health problem because of its high prevalence and associated significant morbidity and mortality. Aim: The objectives of this study were to estimate the pattern of anemia in the elderly patients and the underlying etiology of anemia. Subjects and Methods: This was a hospital-based prospective observational study, conducted in patients aged 60 years and above at SSIMS, T. Begur. Anemia is defined as hemoglobin level less than $13 \mathrm{~g} / \mathrm{dl}$ in men and $12 \mathrm{~g} / \mathrm{dl}$ in women. Results: Among the 100 older patients with anemia, the mean value of hemoglobin was $8.9 \pm 2.3 \mathrm{~g} / \mathrm{dl}$. The etiological distribution of anemia was iron deficiency in 25 patients $(25 \%)$, chronic disease in 22 patients (22\%), hematological disorders in 20 (20\%), chronic kidney disease in 12 (12\%), multifactorial in 8 (8\%), vitamin B12 deficiency in $3(3 \%)$, folate deficiency in $1(1 \%)$, and hypothyroidism in 1 patient (1\%). No etiology could be found in 8 patients $(8 \%)$. $57.6 \%$ of the iron-deficient patients had upper gastrointestinal lesions and 30.7\% had a nutritional cause. Common chronic diseases causing anemia were malignancy (36.6\%) and liver disease (29.1\%). The myelodysplastic syndrome was the commonest hematological disorder. 53.35\% of the patients had normocytic anemia, $40 \%$ had microcytic anemia, and $6.6 \%$ had macrocytic anemia. Conclusion: In most of the cases, anemia in the elderly had a treatable cause. Thus, a thorough investigation including gastrointestinal endoscopy is warranted. Unexplained progressive or unresponsive anemia requires bone marrow examination.

Keywords: Anemia, elderly, geriatrics.

Corresponding Author: Dr. R P Buden, M.D. Gen Medicine, Assistant Professor, Dept of Gen Medicine, SSIMS Medical College , T Begur Nelamangala Tq, Bengaluru Rural Dist.

Received: October 2019

Accepted: October2019

\section{Introduction}

Iron deficiency is the most prevalent nutritional deficiency worldwide. This metal ion is an essential element in a variety of physiological processes in human beings, including the production of energy in the brain. Iron is also an enzymatic cofactor in the synthesis of neurotransmitters and myelin and is well known for being especially important as a means of oxygen transportation. The main consequence of iron deficiency is anemia, a common condition and significant problem in the older population. However, many physicians continue to neglect the significance of anemia as a serious clinical condition in the elderly. While decreased hemoglobin levels were previously largely considered a normal consequence of aging, there is now evidence that anemia is associated with an increased risk for morbidity and mortality. According to hemoglobin (Hb) cut-off levels defined by the World Health Organization (WHO) $(<12 \mathrm{~g} / \mathrm{dL}$ for females, $<13 \mathrm{~g} / \mathrm{dL}$ for males), anemia is present in $10 \%$ of women and $11 \%$ of men over the age of 65 , increasing to $20 \%$ of women and $26 \%$ of men over 85 . An even higher prevalence is seen in hospitalized patients, of whom approximately $40-50 \%$ have been found to be anemic. The primary consequences of anemia, even mild anemia in which hemoglobin values are only marginally reduced $(>9.5 \mathrm{~g} / \mathrm{dL})$, are the impairment of functional capacities and a reduced quality of life. Furthermore, in elderly persons, anemia can impair physical performance and mobility, thus increasing the risk of falls. An association between anemia in older adults and mortality has been observed in several studies, even in the absence of concomitant illness. In elderly patients, anemia is often overlooked, despite the fact that it has been shown to have potentially serious consequences.

\section{Subjects and Methods}

\section{Study Population}

This was a hospital-based prospective observational study, conducted in a tertiary care center of South India, from November 2018 to October 2019.

\section{Case Definition}

Older patients aged 60 years and above presenting to the medical outpatient department or medicine ward of Internal Medicine at SSIMS, T Begur, with clinically suspected and laboratory-confirmed anemia were included. World Health Organization (WHO) criteria, hemoglobin values less than 
$12 \mathrm{~g} / \mathrm{dl}$ in women and less than $13 \mathrm{~g} / \mathrm{dl}$ in men, were used to define anemia. We excluded patients who had received a blood transfusion during the last 12 weeks and patients on chemotherapy or radiotherapy.

Standard protocol approvals and patient consent: The Institutional Ethics Committee approved the study. We obtained written informed consent from all study participants.

\section{Data Collection}

The number of patients enrolled during the study period determined the sample size. On enrolment, a clinical research form including a medical and dietary history, sociodemographic data, and physical examination was completed, and samples of blood, urine, and stool were collected. If the clinical condition permitted it, a bone marrow aspirate was obtained under local anesthesia. All conditions were managed according to standard protocols.

\section{Laboratory Assays}

A complete blood count, including red blood cell (RBC) count, i.e. hemoglobin, hematocrit, reticulocyte count; RBC indices, i.e. mean cell volume (MCV), mean cell hemoglobin $(\mathrm{MCH}), \mathrm{MCH}$ concentration, red cell distribution width; white blood cell count (cell differential and nuclear segmentation of neutrophils); platelet count; and cell morphology, i.e. cell size, hemoglobin content, anisocytosis, poikilocytosis, and polychromasia, was performed. Serum iron study including serum iron, total iron binding capacity, and serum ferritin was done for all patients. Serum levels of folate and vitamin $\mathrm{B}_{12}$ were done in patients with dimorphic and macrocytic anemia or in patients with normocytic or microcytic blood picture in which no other cause of anemia was found. Hemoglobin electrophoresis was done in patients with reduced $\mathrm{MCV}$ or $\mathrm{MCH}$ and normal iron studies. Bone marrow studies (aspiration and/or biopsy) were carried out on patients with blood smear showing immature white cells or nucleated red cells, indeterminate status of iron stores and unexplained progressive or unresponsive anemia. Renal function tests including blood urea and serum creatinine were done for all. Additional investigations or diagnostic procedures (including radiological imaging, gastrointestinal (GI) endoscopy, tissue biopsy, stool analysis, thyroid function test, etc.) were performed when judged to be appropriate.

\section{Statistical Analysis}

We used Statistical Package for the Social Sciences (SPSS), version 16 for Windows, for data analysis, and recorded discrete data as frequency and percentage, and symmetrically distributed continuous data as mean $\pm \mathrm{SD}$. The study subjects were categorized into three groups according to age (of age 60-69 years, 70-79 years, and 80 years and above). Similarly, study groups were categorized into different types of anemia by MCV values, such as normocytic, microcytic, and macrocytic anemia. Differences in the mean values were analyzed using the ANOVA test. Differences in the type of anemia by age groups, gender, and other variables were analyzed using Chi-square test. $P<0.05$ was considered statistically significant.

\section{Results}

\section{Baseline Characteristics}

We enrolled 100 patients aged 60 years and above with anemia according to WHO definition. The mean age was $68.1 \pm 7.8$ years, ranging from 60 to 92 years. The male to female ratio was 1.6:1 and there was an almost equal distribution of rural (50.5\%) and urban population (49.5\%).

\section{Clinical and Laboratory Spectrum of Anemia}

Easy fatigability was the most common complaint, seen in $86.7 \%$ of patients followed by weakness $(80 \%)$, shortness of breath $(45.7 \%)$, swelling of feet $(22.9 \%)$, headache $(19 \%)$, vertigo $(18.1 \%)$, palpitation $(14.3 \%)$, bleeding $(12.4 \%)$, and tinnitus $(6.7 \%)$. Vertigo was more common in older patients aged 80 years and above and was found in $28.6 \%$ of cases of this age group.

On physical examination, pallor was the most common finding, noted in $84.8 \%$ of patients; peripheral edema $(21.9 \%)$ and glossitis $(9.5 \%)$ were next common findings.

The mean value of hemoglobin was $8.9 \pm 2.3 \mathrm{~g} / \mathrm{dl}$ with a range of 3.9-13 g/dl. Older age group of 80 years and above had lower mean hemoglobin $(7.5 \mathrm{~g} / \mathrm{dl})$.

Anemia characterization based on RBC indices and peripheral smear revealed that normocytic anemia was the most common type, seen in $53.3 \%$ of patients followed by microcytic anemia (40\%) and macrocytic anemia (6.6\%). $56.1 \%$ patients were pure vegetarians and microcytic anemia was more common in this group (45.8\%). Chronic alcohol consumption was noted in $37.1 \%$ elderly patients. Normocytic anemia was present in $53.8 \%$ of all alcohol consumers, microcytic anemia in $35.9 \%$, and macrocytic anemia in $10.3 \%$.

\begin{tabular}{l} 
Table 1: Etiological classification of anemia in the 105 older \\
patients \\
\begin{tabular}{|l|l|}
\hline Causes & Number $(\%)$ \\
\hline Iron deficiency anemia & $25(25 \%)$ \\
\hline Chronic gastritis & 8 \\
\hline Upper gastrointestinal ulcer & 3 \\
\hline Nutritional & 5 \\
\hline Gastrointestinal malignancy & 2 \\
\hline Others & 7 \\
\hline Anemia of chronic disease & $22(22 \%)$ \\
\hline Solid tumor malignancy & 7 \\
\hline Chronic liver disease & 6 \\
\hline Chronic infection & 4 \\
\hline Chronic inflammatory condition & 2 \\
\hline Others & 3 \\
\hline Chronic kidney disease & $12(12 \%)$ \\
\hline Hematological disorder & $20(20 \%)$ \\
\hline Myelodysplastic syndrome & 4 \\
\hline Multiple myeloma & 2 \\
\hline Chronic lymphoproliferative disease & 3 \\
\hline Chronic myeloproliferative disease & 3 \\
\hline Non-Hodgkin lymphoma & 3 \\
\hline Hodgkin Lymphoma & 1 \\
\hline Aplastic anemia & 2 \\
\hline Beta thalassemia & 2 \\
\hline Folate/vitamin B12 deficiency & $3(3 \%)$ \\
\hline Hypothyroidism & $1(1 \%)$ \\
\hline Multi-factorial cause & $8(8 \%)$ \\
\hline Unexplained cause & $9(9 \%)$ \\
\hline & \\
\hline &
\end{tabular} \mid \\
\hline
\end{tabular}

\section{Etiological Classification}

Among the 100 patients, the etiological distribution of anemia was iron deficiency anemia (IDA) in 25 patients 
(25\%), anemia in chronic disease (ACD) in 22 patients (22\%), hematological disorders in $20(20 \%)$, chronic kidney disease $(\mathrm{CKD})$ in $12(12 \%)$, mixed in $8(8 \%)$, vitamin $\mathrm{B} 12$ deficiency in $2(2 \%)$, folate deficiency in $1(1 \%)$, and hypothyroidism in 1 patient $(1 \%)$. No etiology for anemia could be found in $8(8 \%)$ patients [Table 1].

Among the 25 cases of IDA, upper GI lesions were observed in 15 patients, which included chronic gastritis in 8 , peptic ulcer disease with bleed in 3 , esophagitis with hiatus hernia in 2 , carcinoma esophagus in 1, and celiac disease in 1 . Lower GI lesions were seen in four patients, i.e. adenocarcinoma, terminal ileal ulcers, and ulcer cecum. GI malignancy was found in two of IDA patients. Nutritional IDA was seen in five patients.

In our study, ACD was found in 24 patients. Common underlying chronic diseases were malignancy in 8 and chronic liver disease in 7 patients. Other causes of chronic inflammation noticed were pulmonary tuberculosis, rheumatoid arthritis, reactive arthritis, left ventricular failure, angiodysplasia, pulmonary aspergillosis, and liver abscess.

In our study, 21 cases were due to hematological disorders. Out of these, 16 patients were having malignant hematological disorders including myelodysplastic syndrome (MDS) in 4 , multiple myeloma in 2 , chronic lymphoproliferative disease in 3 , chronic myeloproliferative disease in 3 , Non-Hodgkin disease in 3 , and Hodgkin disease in 1 . Five patients were having non-neoplastic hematological disorders which included beta-thalassemia trait in three and aplastic anemia in two.

\section{Discussion}

Using WHO criteria for anemia, 100 patients of age 60 years and above were included, and underwent complete clinical evaluation and laboratory investigations. Anemia was evaluated in a manner similar to that in younger adults. MCV was used to classify anemia into microcytic, normocytic, and macrocytic anemia. Normocytic anemia was the most common type in our study, seen in more than half of cases, similar to previous studies.

Table 2: Major causes of anemia in geriatrics: Comparison of different studies

\begin{tabular}{|l|l|l|l|l|l|l|}
\hline & $\begin{array}{l}\text { Guraln } \\
\text { iket al. } \\
\mathbf{2 0 0 4}\end{array}$ & $\begin{array}{l}\text { Tettama } \\
\text { ntiet al. } \\
\mathbf{2 0 1 0}\end{array}$ & $\begin{array}{l}\text { Bhasi } \\
\text { net al. } \\
\mathbf{2 0 1 1}\end{array}$ & $\begin{array}{l}\text { Artz } \\
\text { et al. } \\
\mathbf{2 0 1 1}\end{array}$ & $\begin{array}{l}\text { Petrosy } \\
\text { anet al. } \\
\mathbf{2 0 1 2}\end{array}$ & $\begin{array}{l}\text { Our } \\
\text { stu } \\
\text { dy } \\
\mathbf{2 0 1 8}\end{array}$ \\
\hline $\begin{array}{l}\text { Anemia of } \\
\text { chronic } \\
\text { disease }\end{array}$ & 33.6 & 17 & 27 & 10 & 62.1 & 22 \\
\hline $\begin{array}{l}\text { Iron } \\
\text { deficiency } \\
\text { anemia }\end{array}$ & 16 & 16 & 30 & 25 & 30.5 & 25 \\
\hline $\begin{array}{l}\text { Chronic } \\
\text { kidney } \\
\text { disease }\end{array}$ & 12 & 15 & 21 & 3.5 & 17.8 & 12 \\
\hline $\begin{array}{l}\text { Vitamin } \\
\text { B12/folate } \\
\text { deficiency }\end{array}$ & 14.3 & 10 & 5 & 3.4 & 38.9 & 3 \\
\hline $\begin{array}{l}\text { Hematolo } \\
\text { gical } \\
\text { malignanc } \\
\text { y }\end{array}$ & NA & 7.4 & 6 & NA & 6.3 & 20 \\
\hline $\begin{array}{l}\text { Unexplain } \\
\text { ed }\end{array}$ & 24 & 26 & 2 & 44 & 8.4 & 9 \\
\hline
\end{tabular}

Further evaluation for underlying etiology showed that IDA was the most prevalent anemia, just outnumbered the ACD (25\% vs $22 \%$ ) [Table-2].

Upper GI endoscopy performed in patients with IDA with no obvious cause showed that chronic upper GI blood loss, including occult blood from chronic gastritis, peptic ulcer disease, esophagitis, and carcinoma esophagus constitute $53.8 \%$ of IDA cases. Insufficient dietary intake is still a common cause of iron deficiency in developing countries like India, and was seen in $19.2 \%$ of our IDA cases.

In older adults, inflammatory conditions are frequently linked with anemia. A recent study found inflammatory disorders in 70\% cases of anemia in 191 hospitalized elderly patients, of which $60 \%$ had concomitant CKD. Our study found ACD in $22 \%$ cases and CKD in another $12 \%$ cases of anemia. In $\mathrm{ACD}$, pro-inflammatory cytokines suppress erythropoiesis and shorten RBC survival. In older age, subtle pro-inflammatory changes may lead to clinically significant anemia.

Benign hematological causes of anemia like hemolytic anemia, thalassemia, aplastic anemia, etc. are seen more frequently in younger age group. Conversely, malignant hematological disorders like MDS, myeloma, chronic lymphoproliferative disorder, chronic myeloproliferative disorder, and lymphoma are common in older age. Our sample included $20 \%$ of elderly patients with malignant hematological disorders and anemia, a higher prevalence than previous studies. MDS should be a diagnostic consideration when other cell lineages are involved. Multiple myeloma is also an important cause of anemia in the elderly. A high index of suspicion is required for this possibility when anemia is associated with back pain, hypercalcemia, or renal failure.

In our study, $7.6 \%$ of elderly patients had more than one cause for their anemia. Multi-factorial etiology is common among elderly, and some studies found more than one cause of anemia in more than half of the cases. Alcohol consumption and medications are important contributors to anemia in this age group. In our study, $37.1 \%$ of patients were found to be chronic alcohol consumers.

The cause of anemia remained unexplained only in $8.6 \%$ of cases. Previous studies found no cause of anemia in at least one-fourth of elderly patients.

Postulated underlying mechanisms for unexplained anemia in older adults are early myelodysplasia, malnutrition, hypogonadism, low glomerular filtration rate and relative erythropoietin deficiency.

The limitation of our study was a hospital-based enrolment of cases. Asymptomatic patients or patients with mild anemia may not have reported to the health center. Further population-based studies are needed to ascertain the prevalence and etiology of anemia in the older population of India and to elucidate the impact of disease on this age group.

\section{Conclusion}

Given the rising numbers of older adults in India, family physicians require greater attention to evaluate and manage common treatable conditions such as anemia, which may lead to increased morbidity and mortality in this particular 


\section{Buden: Anaemia in Geriatric Patients.}

population. This prospective study shows that in most of the cases, anemia in the elderly has a treatable cause. Thus, a thorough investigation including GI endoscopy is warranted. Unexplained progressive or unresponsive anemia requires bone marrow examination.

\section{Financial support and sponsorship}

Nil.

\section{References}

1. Stauder R, Valent P, Theurl I. Anemia at older age: Etiologies, clinical implications, and management. Blood.2018;131:505-14.

2. Halawi R, Moukhadder H, Taher A. Anemia in the elderly: A consequence of aging? Expert Rev Hematol. 2017;10:327-35.

3. S. D. Denny, M. N. Kuchibhatla, and H. J. Cohen, "Impact of anemia on mortality, cognition, and function in community-dwelling elderly," American Journal of Medicine, vol. 119, no. 4, pp. 327-334, 2006.

4. BeghéC, Wilson A, Ershler WB. Prevalence and outcomes of anemia in geriatrics: A systematic review of the literature. Am J Med.
2004;116(Suppl 7A):3S-10S.

5. Penninx BW, Guralnik JM, Onder G, Ferrucci L, Wallace RB, Pahor $\mathrm{M}$. Anemia and decline in physical performance among older persons. Am J Med. 2003;115:104-10.

6. Chaves PH, Semba RD, Leng SX, Woodman RC, Ferrucci L, Guralnik $\mathrm{JM}$, et al. Impact of anemia and cardiovascular disease on frailty status of community-dwelling older women: The women's health and aging studies I and II. J Gerontol A BiolSci Med Sci. 2005;60:729-35.

7. Atti AR, Palmer K, Volpato S, Zuliani G, Winblad B, Fratiglioni L. Anaemia increases the risk of dementia in cognitively intact elderly. Neurobiol Aging. 2006;27:278-84.

8. Onder G, Penninx BW, Cesari M, Bandinelli S, Lauretani F, Bartali B, et al. Anemia is associated with depression in older adults: Results from the InCHIANTI study. J Gerontol A BiolSci Med Sci. 2005;60:1168-72.

9. Chaves PH, Ashar B, Guralnik JM, Fried LP. Looking at the relationship between hemoglobin concentration and prevalent mobility difficulty in older women: Should the criteria currently used to define anemia in older people be reevaluated? J Am Geriatr Soc. 2002;50:1257-64.

10. Dharmarajan TS, Norkus EP. Mild anemia and the risk of falls in older adults from nursing homes and the community.J Am Med Dir Assoc.2004;5:395-400

Copyright: (C) the author(s), 2019. It is an open-access article distributed under the terms of the Creative Commons Attribution License (CC BY 4.0), which permits authors to retain ownership of the copyright for their content, and allow anyone to download, reuse, reprint, modify, distribute and/or copy the content as long as the original authors and source are cited work is properly cited.

How to cite this article: Buden RP. A Study of Clinical and Etiologigal Profile of Anaemia in Geriatric Patients in a Tertiary Care Hospital. Acad. J Med. 2019;2(2):114-17.

DOI: dx.doi.org/10.21276/ajm.2019.2.2.28 